\title{
The relationship between insomnia symptoms and work productivity among blue-collar and white-collar Japanese workers engaged in construction/civil engineering work: a cross-sectional study
}

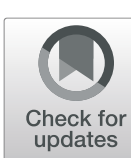

Momoko Kayaba ${ }^{1,2}$, Taeko Sasai-Sakuma ${ }^{1,2,3}$, Yoshikazu Takaesu ${ }^{4,5}$ and Yuichi Inoue ${ }^{1,2^{*}}$

\begin{abstract}
Background: The situation of work productivity loss due to sleep disorders/problems among workers in industrialized societies remains unclear. The purpose of this study was to clarify the prevalence of insomnia symptoms and actual situation of work productivity by job type (white-collars/blue-collars) among construction/civil engineering workers in Japan and evaluate the association between insomnia symptoms and work productivity adjusting for sleep duration and sociodemographic, work-related, and health-related variables.

Methods: This cross-sectional study included 17,828 construction/civil engineering workers (15,837 males and 1991 females) aged 40 to 74 years in Japan. The questionnaire consisted of socio-demographic characteristics, information on work productivity (work performance and absence), respective insomnia symptoms (difficulty initiating sleep; DIS, difficulty maintaining sleep; DMS, and early morning awakening; EMA), bedtime schedule, workrelated factors (job type, working hours), and perceived health condition. To identify the associated factors of work productivity, the logistic regression analyses were conducted.
\end{abstract}

Results: The percentages of workers who reported to be experiencing DIS, DMS, and EMA were 7.9, 16.3, and $13.1 \%$, respectively. Poor work performance was associated with every insomnia symptom in both the blue-collar and white-collar workers. Meanwhile, absence was associated with DIS in blue-collar workers and both DIS and DMS in white-collar workers; however, not with EMA in both the groups. In blue-collar workers, engagement in shift work was associated with poor work performance.

Conclusions: The present study revealed the association between insomnia symptoms and work productivity, suggesting the necessity of early prevention of insomnia among both blue-collar and white-collar workers.

Keywords: Work productivity, Work performance, Absenteeism, Insomnia, Blue-collar worker, Shift work

\footnotetext{
* Correspondence: inoue@somnology.com

'Department of Somnology, Tokyo Medical University, 6-7-1 Nishishinjuku, Shinjuku-ku, Tokyo 160-0023, Japan

${ }^{2}$ Japan Somnology Center, Institute of Neuropsychiatry, 5-10-10, Yoyogi,

Shibuya-ku, Tokyo 151-0053, Japan

Full list of author information is available at the end of the article
}

C C The Author(s). 2021 Open Access This article is licensed under a Creative Commons Attribution 4.0 International License, which permits use, sharing, adaptation, distribution and reproduction in any medium or format, as long as you give appropriate credit to the original author(s) and the source, provide a link to the Creative Commons licence, and indicate if changes were made. The images or other third party material in this article are included in the article's Creative Commons licence, unless indicated otherwise in a credit line to the material. If material is not included in the article's Creative Commons licence and your intended use is not permitted by statutory regulation or exceeds the permitted use, you will need to obtain permission directly from the copyright holder. To view a copy of this licence, visit http://creativecommons.org/licenses/by/4.0/. The Creative Commons Public Domain Dedication waiver (http://creativecommons.org/publicdomain/zero/1.0/) applies to the data made available in this article, unless otherwise stated in a credit line to the data. 


\section{Background}

Loss of work productivity due to presenteeism, namely, the worker although being at work is less productive because of health problems, has recently drawn social attention [1]. The conditions causing loss of work productivity include various diseases such as, migraine, allergic rhinitis, depression, low back pain, and rheumatoid arthritis [2, 3]. Sleep disturbance also impairs daytime function, possibly leading to the loss of work productivity. Espie et al. reported that weekly frequency of symptom occurrence, morbidity duration, symptom constituents including difficulty falling asleep, and early morning awakening were significantly associated with presenteeism among workers of a global manufacturing company [4]. In addition, they showed that the levels of presenteeism varied depending on job type (office workers < retail; service workers < plant workers) and gender (male and female). A study using the United States (US) poll data also reported that presenteeism and absenteeism were associated with insomnia, obstructive sleep apnea, and restless legs syndrome; however, not with shift workers and shift work disorders [5]. A nationwide study confirmed the association between insomnia and both presenteeism and absenteeism after adjusting for sociodemographic characteristics and health status [6]. Another US nationwide study reported association of insomnia with presenteeism; however, not with absenteeism after other comorbid conditions were controlled [7].

Only a few studies have investigated the association between these problems and work productivity after adjustment of work-related factors (e.g., job type, work hours, shift work), which may be the confounders $[4,8]$. According to previous studies on the relationship between work-related factors and workers' health, psychological distress was more prevalent among bluecollar workers [9, 10] and shift workers [11]. Hilton et al. reported that productivity decrement due to psychological distress was higher in the blue-collar workers (25\%) than in white-collar workers (6\%) [12]. Considering this, this study was conducted: 1) to clarify the prevalence of insomnia symptoms and the actual situation of work productivity by job type (i.e., whitecollars/blue-collars) among construction/civil engineering workers in Japan, and 2) to evaluate the association between insomnia symptoms and work productivity after adjustment of sleep duration and sociodemographic, work-related (i.e., shift work and working hours), and health-related variables.

\section{Methods}

\section{Study design and population}

Ethical approval for this study was obtained from the Ethical Committee of Japan Depression Center (No.2019_
0002). This manuscript was written in accordance with the STROBE statement for cross-sectional studies and the checklist was cited as Additional file 1.

As a part of the health management of employees, the questionnaire was distributed to workers belonging to the health insurance society of construction/civil engineering in Japan. The present study analyzed the data of workers who gave informed consent for the questionnaire use for research purposes. Between April 2018 and March 2019, 26,773 workers aged 40 to 74 years, who received an annual specified medical checkup, responded to the questionnaire. Out of these, 8945 respondents were excluded according to the following exclusion criteria: lack of information whether living alone or not ( $n=229)$, work performance $(n=541)$, number of days of absence in the previous 4 weeks $(n=1270)$, job type $(n=1925)$, working pattern $(n=3464)$, number of working days per week $(n=264)$ or working hours per week $(n=116)$, perceived physical health condition $(n=89)$, perceived mental health condition $(n=48)$, bedtime and wake-up time on weekdays and on weekends $(n=773)$, and presence/absence of subjective insomnia $(n=152)$. Finally, the completed data of 17,828 workers were analyzed for the present study.

\section{Measures}

Among the socio-demographic variables, data on age and sex were collected by the insurance register. Other variables such as whether they were living alone or not, presence or absence of respective insomnia symptoms (difficulty initiating sleep; DIS, difficulty maintaining sleep; DMS, and early morning awakening; EMA), bedtime and wake-up time on weekdays and on weekends, job type (white-collars: designer, sales, clerical staff, or manager/blue-collars: field worker or overseer), working pattern (daytime work/shift work), number of working days per week, working hours per week (shorter than 40 $\mathrm{h} / 40-60 \mathrm{~h} / 60 \mathrm{~h}$ or longer), and perceived physical and mental health conditions (poor: very poor or poor/not poor: average, good, or very good) were self-reported or through rated questionnaire. Sleep duration on weekdays and weekends were calculated based on participants' bedtime and wake-up time, following which that on weekdays was categorized into three groups (shorter than $7 \mathrm{~h} / 7-8 \mathrm{~h} / 8 \mathrm{~h}$ or longer) for subsequent analyses considering a U-shaped relationship (see Background). The work performance in the previous 4 weeks was assessed on a scale of $0 \%$ ("total lack of performance") to $100 \%$ ("no lack of performance") in units of $10 \%$, while the absence was measured by asking the number of days an employee was absent for illness or injury in the same duration by using question items from the World Health Organization Health and Work Performance Questionnaire [13]. Work performance was converted into a binary 
outcome based on the median value. Absence was defined as the absence of more than a day in the previous 4 weeks.

\section{Statistical analysis}

Representative values are shown as mean \pm standard deviation. For comparisons between the groups of bluecollar and white-collar workers, the Wilcoxon's rank sum test for continuous variables and Pearson's Chisquared test for categorical variables were used. To identify the associated factors of work productivity in white-collar and blue-collar, sub-group analyses using a logistic regression model were performed in which the response variables were work performance $(90-100 \% /<$ 90\%) and absence, (None/ $\geq 1$ day) and explanatory variables were presence of DIS, DMS, and EMA, adjusting for age, sex, and whether the workers lived alone, sleep duration on weekdays (less than $7 \mathrm{~h}, 7-8 \mathrm{~h}, 8 \mathrm{~h}$ or longer), perceived physical health condition (good or average/poor), perceived mental health condition (good or average/poor), working pattern (daytime work/shift work), and hours engaged in work per week (shorter than $40 \mathrm{~h} / 40-60 \mathrm{~h} / 60 \mathrm{~h}$ or longer). In the logistic regression model, the degree of association was represented as adjusted odds ratio (aOR) and 95\% confidence interval (95\%CI). Statistical significance was set at $p<0.05$. Statistical analyses were performed using $\mathrm{R}$ statistical software version 3.5.1 (R Core Team, Vienna, Austria), "caret" package [14], and "Resource Selection" package [15].

\section{Results}

\section{Worker subjects' characteristics}

Sociodemographic, work-related, and health-related variables as well as sleep-related variables among the subject workers are shown in Table 1 . The mean age was $52.5 \pm$ 7.6 years (range: $40-74$ years). A clear male predominance $(88.8 \%)$ was observed, and $23.2 \%$ of the participants lived alone. About half of the workers were categorized as blue collar (40.9\%), and $4.7 \%$ of the workers were engaged in shift work. The mean working days per week were $5.2 \pm 0.5$ days, with $17.2 \%$ of the workers working for less $40 \mathrm{~h}, 70.0 \%$ between 40 and $60 \mathrm{~h}$, and $12.8 \%$ workers for $60 \mathrm{~h}$ or longer. The poor physical health was perceived in $12.5 \%$ of the workers, while $11.3 \%$ had poor mental health. The workers slept for an average of $6.3 \pm 1.0 \mathrm{~h}$ on weekdays and $7.6 \pm 1.2 \mathrm{~h}$ on weekends. There were $23.4 \%$ workers with sleep duration shorter than $7 \mathrm{~h}$ on weekdays, $69.5 \%$ had between 7 and $8 \mathrm{~h}$, and $7.1 \%$ had $8 \mathrm{~h}$ or longer sleep duration.

\section{Prevalence of insomnia symptoms}

The percentages of workers who reported to be experiencing DIS, DMS, and EMA were 7.9, 16.3, and 13.1\%, respectively. In all, $72.7 \%$ of workers reported no insomnia symptoms. Compared to the blue-collar workers, age $(p<0.001)$ and the percentage of female workers $(p<0.001)$ were higher, the percentages of workers who lived alone $(p<0.001)$ and those who were engaged in shift work $(p<0.001)$ were lower, working days $(p<0.001)$, working time $(p<0.001)$, and sleep duration $(p<0.001)$ were shorter, mental health $(p<0.01)$ and work performance $(p<0.001)$ were better, while absence $(p<0.001)$ was more prevalent among white-collar workers. Despite these significant differences, the prevalence of insomnia symptoms did not differ between the blue-collar and white-collar workers $(p>0.2)$.

\section{Work productivity}

The median work performance was $90 \%$. The percentage of workers who were absent due to sickness or injury for the previous 4 weeks was $9.3 \%$. The mean number of absent days for the absentee workers during the study period was $3.0 \pm 3.9$ days.

The percentage of workers who had poor work performance was significantly higher in blue-collar workers than that in white-collar workers $(56.1 \%>$ $44.9 \%, p<0.001$ ) (Table 1). On the other hand, the percentage of workers with positivity for absence was significantly higher in white-collar workers than in bluecollar workers $(10.1 \%>8.3 \%, \mathrm{p}<0.001)($ Table 1$)$.

\section{Relationship between insomnia symptoms and work productivity}

The results of multiple logistic regression analyses of factors associated with subjectively poor work performance and absences among white-collar and blue-collar workers are outlined in Tables 2 and 3. Poor work performance was positively associated with insomnia symptoms (DIS, DMS, and EMA) among both blue-collar and white-collar workers. Absence was associated with DIS among both blue- and white-collar workers. DMS was only associated with absence in white-collar workers. EMA was not associated with absence in either blue- or white-collar workers.

\section{Discussion}

This is the first study to investigate the difference in the association of insomnia symptoms and work productivity between the blue-collar and white-collar workers engaged in construction/civil engineering work.

In the present study, poor work performance was more prevalent among blue-collar workers. This result was consistent with a previous report in which presenteeism was more severe in plant workers than in office workers [4]. On the other hand, absence was more prevalent among white-collar workers. The percentages of workers with insomnia symptoms were similar between blue-collar and white-collar workers. Work performance was also associated with the respective 
Table 1 Subjects' characteristics, insomnia symptoms and work productivity

\begin{tabular}{|c|c|c|c|c|c|}
\hline & & Total $(n=17,828)$ & Blue-collar $(n=7292)$ & White-collar $(n=10,536)$ & $p$-value \\
\hline Age & (y) & $52.5 \pm 7.6$ & $51.6 \pm 7.8$ & $53.2 \pm 7.4$ & $<0.001^{* *}$ \\
\hline \multicolumn{6}{|l|}{ Sex } \\
\hline Male & n (\%) & $15,837(88.8)$ & $7175(98.4)$ & $8662(82.2)$ & \multirow[t]{2}{*}{$<0.001^{* *}$} \\
\hline Female & n (\%) & $1991(11.2)$ & 117 (1.6) & $1874(17.8)$ & \\
\hline \multicolumn{6}{|l|}{ Living alone } \\
\hline No & n (\%) & $4133(23.2)$ & $5181(71.1)$ & $8514(80.8)$ & \multirow[t]{2}{*}{$<0.001^{* *}$} \\
\hline Yes & n (\%) & $13,695(76.8)$ & $2111(28.9)$ & $2022(19.2)$ & \\
\hline \multicolumn{6}{|l|}{ Working pattern } \\
\hline Daytime worker & n (\%) & $16,711(93.7)$ & $6452(88.5)$ & $10,259(97.4)$ & \multirow[t]{2}{*}{$<0.001^{* *}$} \\
\hline Shift worker & n (\%) & $834(4.7)$ & $795(10.9)$ & $39(0.4)$ & \\
\hline \multicolumn{6}{|l|}{ Working time } \\
\hline $40-60 h$ & n (\%) & $12,470(69.9)$ & $4861(66.7)$ & 7609 (72.2) & \multirow[t]{3}{*}{$<0.001^{* *}$} \\
\hline$<40 \mathrm{~h}$ & n (\%) & $3068(17.2)$ & $783(10.7)$ & $2285(21.7)$ & \\
\hline$\geq 60 \mathrm{~h}$ & n (\%) & $2290(12.8)$ & $1648(22.6)$ & $642(6.1)$ & \\
\hline Working days & (day/week) & $5.2 \pm 0.5$ & $5.5 \pm 0.6$ & $5.1 \pm 0.3$ & $<0.001^{* *}$ \\
\hline \multicolumn{6}{|l|}{ Physical health } \\
\hline Good/average & n (\%) & $15,603(87.5)$ & $6371(87.4)$ & $9232(87.6)$ & \multirow[t]{2}{*}{0.631} \\
\hline Poor & n (\%) & $2225(12.5)$ & $921(12.6)$ & $1304(12.4)$ & \\
\hline \multicolumn{6}{|l|}{ Mental health } \\
\hline Good/average & n (\%) & $15,807(88.7)$ & $6393(87.7)$ & $9414(89.4)$ & \multirow[t]{2}{*}{$<0.01^{*}$} \\
\hline Poor & n (\%) & $2021(11.3)$ & $899(12.3)$ & $1122(10.6)$ & \\
\hline \multicolumn{6}{|l|}{ Sleep duration } \\
\hline $7-8 \mathrm{~h}$ & n (\%) & $4179(23.4)$ & $795(24.2)$ & $2415(22.9)$ & \multirow[t]{3}{*}{$<0.001^{* *}$} \\
\hline$<7 \mathrm{~h}$ & n (\%) & $12,385(69.5)$ & $4884(67.0)$ & $7501(71.2)$ & \\
\hline$\geq 8 \mathrm{~h}$ & n (\%) & $1264(7.1)$ & $644(8.8)$ & $620(5.9)$ & \\
\hline \multicolumn{6}{|l|}{ Insomnia symptoms } \\
\hline DIS & n (\%) & $1410(7.9)$ & $568(7.8)$ & $842(8.0)$ & 0.643 \\
\hline DMS & n (\%) & $2914(16.3)$ & $1166(16.0)$ & $1748(16.6)$ & 0.296 \\
\hline EMA & n (\%) & $2335(13.1)$ & $928(12.7)$ & 1407 (13.4) & 0.230 \\
\hline \multicolumn{6}{|l|}{ Work performance } \\
\hline $90-100 \%$ & n (\%) & 8999 (50.5) & $3198(43.9)$ & $5801(55.1)$ & \multirow[t]{2}{*}{$<0.001^{* *}$} \\
\hline$<90 \%$ & n (\%) & $8829(49.5)$ & $4094(56.1)$ & $4735(44.9)$ & \\
\hline \multicolumn{6}{|l|}{ Absence } \\
\hline None & n (\%) & $16,163(90.7)$ & $6690(91.7)$ & $9473(89.9)$ & \multirow[t]{2}{*}{$<0.001^{* *}$} \\
\hline$\geq 1$ day & n (\%) & $1665(9.3)$ & $602(8.3)$ & $1063(10.1)$ & \\
\hline
\end{tabular}

Values are expressed as mean \pm standard deviation for continuous variables

DIS Difficulty initiating sleep, DMS Difficulty maintaining sleep, EMA Early morning awakening

${ }^{*}<0.05,{ }^{* *}<0.001$

insomnia symptoms among both blue-collar and whitecollar workers. These results suggest that deteriorated work performance is susceptible to any kind of insomnia symptom in both job types. On the other hand, the association between absence and insomnia symptoms differed between them. Among blue-collar workers, absence was associated with DIS, but not with DMS or EMA. In addition to DIS, DMS was also associated with the absence of white-collar workers. These results suggested that DIS was strongly associated with the absence.

Interestingly, our study revealed a significant association between engagement in shift work and poor work performance among blue-collar workers. It is well known that about $20-30 \%$ of shift workers experience night time insomnia symptoms and daytime sleepiness, 
Table 2 Logistic regression model for associated factors with poor work performance

\begin{tabular}{|c|c|c|c|c|}
\hline \multirow[b]{3}{*}{ Explanatory variables } & \multicolumn{2}{|c|}{ Blue-collar $(n=7292)$} & \multicolumn{2}{|c|}{ White-collar $(n=10,536)$} \\
\hline & \multicolumn{2}{|c|}{ Ref. $90-100 \%(n=3198) /<90 \%(n=4094)$} & \multicolumn{2}{|c|}{ Ref. $90-100 \%(n=4735) /<90 \%(n=5801)$} \\
\hline & Crude OR $(95 \% \mathrm{Cl})$ & $\mathrm{aOR}^{\mathrm{a}}(95 \% \mathrm{Cl})$ & Crude OR $(95 \% \mathrm{Cl})$ & $\mathrm{aOR}^{\mathrm{a}}(95 \% \mathrm{Cl})$ \\
\hline Age & $0.98(0.98-0.99)^{* *}$ & $0.98(0.98-0.99)^{* *}$ & $0.99(0.99-1.00)^{*}$ & $0.99(0.99-1.00)^{*}$ \\
\hline \multicolumn{5}{|l|}{ Sex } \\
\hline Male & 1.0 & 1.0 & 1.0 & 1.0 \\
\hline Female & $0.48(0.33-0.70)^{* *}$ & $0.43(0.29-0.63)^{* *}$ & $1.25(1.13-1.38)^{* *}$ & $1.10(0.99-1.23)$ \\
\hline \multicolumn{5}{|l|}{ Living alone } \\
\hline No & 1.0 & 1.0 & 1.0 & 1.0 \\
\hline Yes & $1.29(1.17-1.43)^{* *}$ & $1.23(1.11-1.37)^{* *}$ & $1.13(1.02-1.24)^{*}$ & $1.06(0.96-1.17)$ \\
\hline \multicolumn{5}{|l|}{ Working pattern } \\
\hline Daytime worker & 1.0 & 1.0 & 1.0 & 1.0 \\
\hline Shift worker & $1.39(1.21-1.60)^{* *}$ & $1.40(1.20-1.64)^{* *}$ & $0.99(0.87-1.13)$ & $1.92(1.00-3.80)$ \\
\hline \multicolumn{5}{|l|}{ Working time } \\
\hline $40-60 h$ & 1.0 & 1.0 & 1.0 & 1.0 \\
\hline$<40 h$ & $0.98(0.84-1.14)$ & $1.05(0.89-1.23)$ & $1.30(1.19-1.43)^{* *}$ & $1.31(1.18-1.45)^{* *}$ \\
\hline$\geq 60 \mathrm{~h}$ & $1.39(1.24-1.55)^{* *}$ & $1.24(1.10-1.41)$ & $1.48(1.26-1.74)^{* *}$ & $1.40(1.17-1.67)^{* *}$ \\
\hline \multicolumn{5}{|l|}{ Physical health } \\
\hline Good/average & 1.0 & 1.0 & 1.0 & 1.0 \\
\hline Poor & $2.89(2.47-3.40)^{* *}$ & $2.06(1.73-2.47)^{* *}$ & $2.52(2.23-2.84)^{* *}$ & $1.73(1.52-1.98)^{* *}$ \\
\hline \multicolumn{5}{|l|}{ Mental health } \\
\hline Good/average & 1.0 & 1.0 & 1.0 & 1.0 \\
\hline Poor & $2.84(2.42-3.34)^{* *}$ & $1.82(1.52-2.19)^{* *}$ & $3.18(2.78-3.64)^{* *}$ & $2.23(1.93-2.59)^{* *}$ \\
\hline \multicolumn{5}{|l|}{ Sleep duration } \\
\hline $7-8 \mathrm{~h}$ & 1.0 & 1.0 & 1.0 & 1.0 \\
\hline$<7 \mathrm{~h}$ & $1.01(0.91-1.13)$ & $0.91(0.81-1.02)$ & $1.00(0.91-1.10)$ & $0.95(0.86-1.05)$ \\
\hline$\geq 8 \mathrm{~h}$ & $1.33(1.11-1.60)^{*}$ & $1.41(1.17-1.71)^{* *}$ & $1.30(1.09-1.55)^{*}$ & $1.26(1.05-1.51)^{*}$ \\
\hline \multicolumn{5}{|l|}{ Insomnia symptoms } \\
\hline Without DIS & 1.0 & 1.0 & 1.0 & 1.0 \\
\hline Presence of DIS & $1.74(1.45-2.09)^{* *}$ & $1.26(1.04-1.53)^{*}$ & $1.80(1.56-2.07)^{* *}$ & $1.33(1.14-1.55)^{* *}$ \\
\hline Without DMS & 1.0 & 1.0 & 1.0 & 1.0 \\
\hline Presence of DMS & $1.66(1.46-1.90)^{* *}$ & $1.28(1.11-1.48)^{*}$ & $1.62(1.46-1.79)^{* *}$ & $1.24(1.11-1.39)^{* *}$ \\
\hline Without EMA & 1.0 & 1.0 & 1.0 & 1.0 \\
\hline Presence of EMA & $1.56(1.35-1.80)^{* *}$ & $1.23(1.05-1.44)^{*}$ & $1.67(1.49-1.87)^{* *}$ & $1.34(1.19-1.52)^{* *}$ \\
\hline \multicolumn{2}{|c|}{ Hosmer-Lemeshow goodness of fit test } & $p=0.706$ & & $p=0.350$ \\
\hline
\end{tabular}

OR Odds ratio, $\mathrm{Cl}$ Confidence interval, aOR Adjusted odds ratio, DIS Difficulty initiating sleep, DMS Difficulty maintaining sleep, EMA Early morning awakening ${ }^{*} p<0.05,{ }^{* *} p<0.001$

a aOR indicated OR adjusted for all other explanatory variables

which are the main accepted symptoms of shift work disorder [16-18]. However, in the present study, the association between being engaged in shift work and poor work performance was shown independent of insomnia symptoms. The reason for this phenomenon is unclear; however, circadian misalignment-related symptoms (e.g., fatigue feeling, excessive daytime sleepiness, poor concentration, and mood changes) [19], possibly contributed to a loss in work performance.
In contrast to previous studies that reported a Ushaped association between sleep duration and work productivity $[20,21]$, the present study showed no association of short sleep duration with work productivity, while long sleep duration was associated with poor work performance. The U-shaped association of sleep duration was not confirmed in the present study due to difference in sleep duration among target population between previous studies and our study. The percentage of 
Table 3 Logistic regression model for associated factors with absence

\begin{tabular}{|c|c|c|c|c|}
\hline \multirow[b]{3}{*}{ Explanatory variables } & \multicolumn{2}{|c|}{ Blue-collar $(n=7292)$} & \multicolumn{2}{|c|}{ White-collar $(n=10,536)$} \\
\hline & \multicolumn{2}{|c|}{ Ref. None $(n=6690) / \geq 1$ day $(n=602)$} & \multicolumn{2}{|c|}{ Ref. None $(n=9473) / \geq 1$ day $(n=1063)$} \\
\hline & Crude OR $(95 \% \mathrm{Cl})$ & $\mathrm{aOR}^{\mathrm{a}}(95 \% \mathrm{Cl})$ & Crude OR $(95 \% \mathrm{Cl})$ & $\mathrm{aOR}^{\mathrm{a}}(95 \% \mathrm{Cl})$ \\
\hline Age & $1.02(1.01-1.03)^{* *}$ & $1.02(1.01-1.03)^{* *}$ & $1.01(1.00-1.01)$ & $1.01(1.00-1.02)$ \\
\hline \multicolumn{5}{|l|}{ Sex } \\
\hline Male & 1.0 & 1.0 & 1.0 & 1.0 \\
\hline Female & $1.52(0.83-2.59)$ & $1.35(0.73-2.33)$ & $1.47(1.26-1.71)^{* *}$ & $1.34(1.13-1.58)^{*}$ \\
\hline \multicolumn{5}{|l|}{ Living alone } \\
\hline No & 1.0 & 1.0 & 1.0 & 1.0 \\
\hline Yes & $0.84(0.69-1.01)$ & $0.86(0.70-1.04)$ & $1.16(0.99-1.35)$ & $1.08(0.92-1.26)$ \\
\hline \multicolumn{5}{|l|}{ Working pattern } \\
\hline Daytime worker & 1.0 & 1.0 & 1.0 & 1.0 \\
\hline Shift worker & $0.95(0.74-1.21)$ & $0.92(0.70-1.20)$ & $0.98(0.78-1.20)$ & $0.46(0.07-1.55)$ \\
\hline \multicolumn{5}{|l|}{ Working time } \\
\hline $40-60 h$ & 1.0 & 1.0 & 1.0 & 1.0 \\
\hline$<40 h$ & $1.18(0.91-1.51)$ & $1.04(0.80-1.35)$ & $1.26(1.09-1.46)^{*}$ & $1.15(0.98-1.35)$ \\
\hline$\geq 60 \mathrm{~h}$ & $0.68(0.54-0.85)^{*}$ & $0.77(0.60-0.97)^{*}$ & $0.93(0.70-1.22)$ & $0.93(0.68-1.25)$ \\
\hline \multicolumn{5}{|l|}{ Physical health } \\
\hline Good/average & 1.0 & 1.0 & 1.0 & 1.0 \\
\hline Poor & $2.74(2.24-3.33)^{* *}$ & $2.85(2.25-3.58)^{* *}$ & $3.99(3.45-4.62)^{* *}$ & $3.60(3.04-4.25)^{* *}$ \\
\hline \multicolumn{5}{|l|}{ Mental health } \\
\hline Good/average & 1.0 & 1.0 & 1.0 & 1.0 \\
\hline Poor & $1.55(1.23-1.93)^{* *}$ & $0.96(0.73-1.25)$ & $2.25(1.90-2.65)^{* *}$ & $1.08(0.88-1.31)$ \\
\hline \multicolumn{5}{|l|}{ Sleep duration } \\
\hline $7-8 h$ & 1.0 & 1.0 & 1.0 & 1.0 \\
\hline$<7 \mathrm{~h}$ & $0.86(0.71-1.05)$ & $0.90(0.74-1.10)$ & $0.91(0.79-1.07)$ & $0.87(0.75-1.02)$ \\
\hline$\geq 8 \mathrm{~h}$ & $1.38(1.02-1.84)^{*}$ & $1.30(0.96-1.74)$ & $1.36(1.04-1.76)^{*}$ & $1.25(0.95-1.64)$ \\
\hline \multicolumn{5}{|l|}{ Insomnia symptoms } \\
\hline Without DIS & 1.0 & 1.0 & 1.0 & 1.0 \\
\hline Presence of DIS & $1.76(1.35-2.27)^{* *}$ & $1.56(1.17-2.05)^{*}$ & $1.77(1.45-2.15)^{* *}$ & $1.27(1.02-1.56)^{*}$ \\
\hline Without DMS & 1.0 & 1.0 & 1.0 & 1.0 \\
\hline Presence of DMS & $1.44(1.16-1.76)^{*}$ & $1.15(0.91-1.45)$ & $1.84(1.58-2.13)^{* *}$ & $1.42(1.20-1.67)^{* *}$ \\
\hline Without EMA & 1.0 & 1.0 & 1.0 & 1.0 \\
\hline Presence of EMA & $1.04(0.81-1.32)$ & $0.79(0.60-1.03)$ & $1.32(1.11-1.56)^{*}$ & $0.95(0.78-1.14)$ \\
\hline \multicolumn{2}{|c|}{ Hosmer-Lemeshow goodness of fit test } & $p=0.543$ & & $p=0.156$ \\
\hline
\end{tabular}

OR Odds ratio, $C I$ Confidence interval, aOR Adjusted odds ratio, DIS Difficulty initiating sleep, DMS Difficulty maintaining sleep, EMA Early morning awakening ${ }^{*} p<0.05,{ }^{* *} p<0.001$

a aOR indicated OR adjusted for all other explanatory variables

workers with short sleep duration $(<7 \mathrm{~h})$ were $11-37 \%$ in previous studies $[20,21]$, in contrast to approximately $70 \%$ in our study, which is consistent with the reported rate $(67 \%)$ among Japanese general population in the statistics survey conducted by Ministry of Health, Labour and Welfare [22]. Thus, the high percentage of short sleep duration in the present study might mask the formation of a U-shaped association between sleep duration and decreased work productivity.
This study had some limitations. First, insomnia symptoms were defined using a self-administered questionnaire and did not necessarily represent physicians' diagnoses. Other sleep disorders, including sleep apnea, were not considered in the present study. Thus, a differential diagnosis of insomnia and other sleep disorders could not be made in the present study. In addition, the duration of insomnia morbidity and severity of the respective insomnia symptoms could not be estimated. 
The survey was conducted using a self-administered questionnaire, the repeatability and reliability of which were not assessed. Secondly, the causal relationship between work productivity and related factors could not be ascertained in this cross-sectional study. In addition, the differences in the causes of deteriorated work productivity and insomnia symptoms could not be estimated in the present study. For example, poor work performance and fewer absences among blue-collar workers could have been caused by job-related factors, including allowance for sick pay and sick days. Meanwhile, insomnia symptoms could have been associated with physical activity. However, the results obtained in this study cannot be used to examine these possibilities. According to a 2009 Estonia investigation of the impact of sick-pay cuts-initiated in response to an economic crisis-the percentage of blue-collar workers with low salaries who were on sick leave was lower than that of white-collar workers. These results suggest that lower-income was a major factor hindering them from using their sick-leave days [23]. Future studies should evaluate job-related factors, including the allowance for sick pay or sick days. Third, our study sample may not be a representative of Japanese general workers. However, the present study was thought to provide significant findings in blue-collar and white-collar workers engaged in construction/civil engineering work. Further studies with prospective sleep evaluation and therapeutic interventions would be desirable. Furthermore, we must clarify the relationship between the job description and the meaning of work performance among blue-collar workers.

\section{Conclusions}

The present study revealed the association between insomnia symptoms and work productivity, suggesting the necessity of early prevention of insomnia among workers. In addition, the present study provided significant findings in both blue-collar and white-collar workers engaged in construction/civil engineering work. These findings about the prevalence of insomnia and its symptoms, the accrual situation of work productivity, and its associated factors among construction/civil engineering workers, could cause economic loss as well as possible accidents at the building site. However, further studies with prospective sleep evaluation and therapeutic interventions are needed.

\section{Abbreviations}

EMA: Early morning awakening; DIS: Difficulty initiating sleep; DMS: Difficulty maintaining sleep

\section{Supplementary Information}

The online version contains supplementary material available at https://doi. org/10.1186/s12889-021-11273-y.

Additional file 1. STROBE Statement-Checklist of items that should be included in reports of cross-sectional studies.
Acknowledgements

We would like to thank Editage (www.editage.com) for English language editing.

\section{Authors' contributions}

YT and YI designed the study. MK analysed data, and wrote the initial draft of the manuscript. TS assisted in the interpretation of data and the preparation of the manuscript. TS, YT and YI supervised the manuscript. All authors have contributed to interpretation and critically reviewed the manuscript. All authors approved the final version of the manuscript, and agree to be accountable for all aspects of the work in ensuring that questions related to the accuracy or integrity of any part of the work are appropriately investigated and resolved.

\section{Funding}

This work was supported by the Japan Society for the Promotion of Science [JP17K17534]. The Department of Somnology is an endowment department, supported by an unrestricted grant from Philips Japan Co., Ltd. and Koike Medical Co., Ltd. The funding bodies had no role in the design of the study, data collection, analysis and interpretation of data, and writing of the manuscript.

\section{Availability of data and materials}

The datasets used and/or analyzed during the current study are available from the corresponding author on reasonable request.

\section{Declarations}

\section{Ethics approval and consent to participate}

Ethical approval for this study was obtained from the Ethical Committee of Japan Depression Center (No.2019_0002). The present study analyzed the data of workers who gave informed consent for the questionnaire use for research purposes. This manuscript was written in accordance with the STROBE statement for cross-sectional studies and the checklist was cited as Additional file 1.

\section{Consent for publication}

Not applicable.

\section{Competing interests}

Department of Somnology is an endowment department, supported with an unrestricted grant from Philips Japan Co., Ltd. and Koike Medical Co., Ltd.

\section{Author details}

'Department of Somnology, Tokyo Medical University, 6-7-1 Nishishinjuku, Shinjuku-ku, Tokyo 160-0023, Japan. ${ }^{2} J a p a n$ Somnology Center, Institute of Neuropsychiatry, 5-10-10, Yoyogi, Shibuya-ku, Tokyo 151-0053, Japan. ${ }^{3}$ Department of Clinical Laboratory Science, Faculty of Medical Technology, Teikyo University, Kaga 2-11-1, Itabashi-ku, Tokyo 173-8605, Japan. ${ }^{4}$ Department of Neuropsychiatry, Kyorin University School of Medicine, Shinkawa 6-20-2, Mitaka-shi, Tokyo 181-8611, Japan. ${ }^{5}$ Department of Neuropsychiatry, Graduate School of Medicine, University of the Ryukyus, 207 Uehara, Nishihara, Okinawa 903-0215, Japan.

Received: 26 January 2021 Accepted: 28 May 2021

Published online: 28 June 2021

\section{References}

1. Hemp P. Presenteeism: at work--but out of it. Harv Bus Rev. 2004;82(10) 49-155.

2. Waongenngarm $P$, Areerak $K$, Janwantanakul P. The effects of breaks on low back pain, discomfort, and work productivity in office workers: a systematic review of randomized and non-randomized controlled trials. Appl Ergon. 2018;68:230-9. https://doi.org/10.1016/j.apergo.2017.12.003.

3. Kigozi J, Jowett $\mathrm{S}$, Lewis M, Barton P, Coast J. The estimation and inclusion of Presenteeism costs in applied economic evaluation: a systematic review. Value Health. 2017;20(3):496-506. https://doi.org/10.1016/j.jval.2016.12.006.

4. Espie CA, Pawlecki B, Waterfield D, Fitton K, Radocchia M, Luik Al. Insomnia symptoms and their association with workplace productivity: cross-sectional and pre-post intervention analyses from a large multinational 
manufacturing company. Sleep Health. 2018;4(3):307-12. https://doi.org/10.1 016/j.sleh.2018.03.003.

5. Swanson LM, Arnedt JT, Rosekind MR, et al. Sleep disorders and work performance: findings from the 2008 National Sleep Foundation sleep in America poll. J Sleep Res. 2011;20(3):487-94. https://doi.org/10.1111/j.1365-2 869.2010.00890.x.

6. Bolge SC, Doan JF, Kannan H, Baran RW. Association of insomnia with quality of life, work productivity, and activity impairment. Qual Life Res. 2009;18(4):415-22. https://doi.org/10.1007/s11136-009-9462-6.

7. Kessler RC, Berglund PA, Coulouvrat C, Hajak G, Roth T, Shahly V, et al. Insomnia and the performance of US workers: results from the America insomnia survey. Sleep. 2011;34(9):1161-71. https://doi.org/10.5665/ SLEEP.1230.

8. Guertler D, Vandelanotte C, Short C, Alley S, Schoeppe S, Duncan MJ. The association between physical activity, sitting time, sleep duration, and sleep quality as correlates of presenteeism. J Occup Environ Med. 2015;57(3):3218. https://doi.org/10.1097/JOM.0000000000000355.

9. Marchand A, Durand P, Demers A. Work and mental health: the experience of the Quebec workforce between 1987 and 1998. Work. 2005;25(2):135-42.

10. Schreuder KJ, Roelen CA, Koopmans PC, Groothoff JW. Job demands and health complaints in white and blue collar workers. Work. 2008;31(4):425-32.

11. Torquati L, Mielke Gl, Brown WJ, Burton NW, Kolbe-Alexander TL. Shift work and poor mental health: a meta-analysis of longitudinal studies. Am J Public Health. 2019:109(11):e13-20. https://doi.org/10.2105/AJPH.2019.305278

12. Hilton MF, Scuffham PA, Sheridan J, Cleary CM, Whiteford HA. Mental illhealth and the differential effect of employee type on absenteeism and presenteeism. J Occup Environ Med. 2008;50(11):1228-43. https://doi.org/1 0.1097/JOM.0b013e31818c30a8.

13. Kessler RC, Barber C, Beck A, Berglund P, Cleary PD, McKenas D, et al. The World Health Organization health and work performance questionnaire (HPQ). J Occup Environ Med. 2003;45(2):156-74. https://doi.org/10.1097/01. jom.0000052967.43131.51.

14. Kuhn M. Building predictive models in $\mathrm{R}$ using the caret package. J Stat Softw. 2008;28:1-26.

15. Lele SR, Keim JL, Solymos P. Resource selection (probability) functions for use-availability data. 2019 [cited 2020 Sept 28]. Available from: https://cran.rproject.org/web/packages/ResourceSelection/ResourceSelection.pdf

16. Asaoka S, Aritake S, Komada Y, Ozaki A, Odagiri Y, Inoue S, et al. Factors associated with shift work disorder in nurses working with rapid-rotation schedules in Japan: the nurses' sleep health project. Chronobiol Int. 2013; 30(4):628-36. https://doi.org/10.3109/07420528.2012.762010.

17. Futenma K, Asaoka S, Takaesu Y, Komada Y, Ishikawa J, Murakoshi A, et al. Impact of hypnotics use on daytime function and factors associated with usage by female shift work nurses. Sleep Med. 2015;16(5):604-11. https:// doi.org/10.1016/.jsleep.2014.11.018.

18. Booker LA, Magee M, Rajaratnam SMW, Sletten TL, Howard ME. Individual vulnerability to insomnia, excessive sleepiness and shift work disorder amongst healthcare shift workers. A systematic review. Sleep Med Rev. 2018;41:220-33. https://doi.org/10.1016/j.smrv.2018.03.005.

19. Bin YS, Postnova S, Cistulli PA. What works for jetlag? A systematic review of non-pharmacological interventions. Sleep Med Rev. 2019;43:47-59. https:/ doi.org/10.1016/j.smrv.2018.09.005.

20. Lallukka T, Kaikkonen R, Härkänen T, Kronholm E, Partonen T, Rahkonen $O$, et al. Sleep and sickness absence: a nationally representative register-based follow-up study. Sleep. 2014;37(9):1413-25. https://doi. org/10.5665/sleep.3986.

21. Gingerich SB, Seaverson ELD, Anderson DR. Association between sleep and productivity loss among 598676 employees from multiple industries. Am J Health Promot. 2018;32(4):1091-4. https://doi.org/10.11 77/0890117117722517.

22. Ministry of Health Labour and Welfare. Health survey 2018 [cited 2020 Sep 29]. Available from: https://www.mhlw.go.jp/content/11130500/0004 72937.pdf

23. Aaviksoo E, Kiivet RA. Sickness benefit cuts mainly affect blue-collar workers. Scand J Public Health. 2014;42(6):497-503. https://doi.org/10.1177/1403494 814538559.

\section{Publisher's Note}

Springer Nature remains neutral with regard to jurisdictional claims in published maps and institutional affiliations.

Ready to submit your research? Choose BMC and benefit from:

- fast, convenient online submission

- thorough peer review by experienced researchers in your field

- rapid publication on acceptance

- support for research data, including large and complex data types

- gold Open Access which fosters wider collaboration and increased citations

- maximum visibility for your research: over $100 \mathrm{M}$ website views per year

At BMC, research is always in progress.

Learn more biomedcentral.com/submissions 